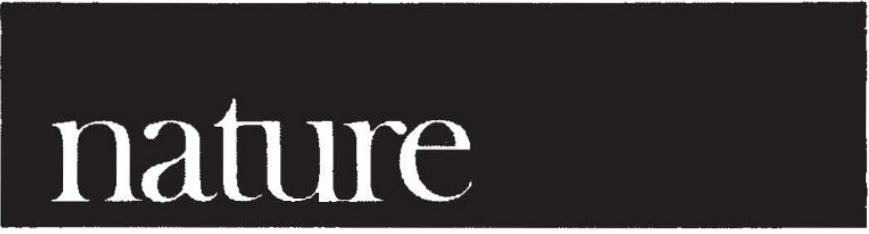

Volume 249

June 21,1974

\section{Rising tide of energy nationalism}

THIS issue of Nature is devoted largely to energy questions as seen by the scientist, from the whisky distillery in Scotland to the cattle dung plants of agricultural India. We cannot claim to be comprehensive in our coverage, but since it is not entirely unfashionable these days to devote large portions of journals to energy considerations it is unlikely that by half way through 1974 anyone who reads at all could claim that he lacked adequate briefing on almost any aspect of the energy situation. And yet it may be that although one can emerge convinced that there are large numbers of competent people in many countries exploring every avenue and leaving no stone unturned, there is still something naggingly wrong with the utterances of policy makers. "Self sufficiency by the 1980s", "indigenous resources", "national energy research strategies". Is not this talk the distant rumblings of a nationalism in science and technology that could make energy as isolated a field to work in as defence?

For some time, of course, marketing of energy has fostered nationalism through the possibilities of economic warfare, and the events of last winter must presumably be called an energy skirmish if nothing else. It is inevitable that countries which have traditionally disliked each other will now use energy as a weapon with no more hesitation than they have used blockades in the past. That is hardly a matter for debate. What is debatable is whether the remarkable nationalism that the energy crisis has engendered even amongst allies can do anything but harm to world order, and lead to tensions where previously there were none, and unnecessary duplication of activity where previously there was collaboration.

The disturbing thing for a scientist is not just that the possession of energy should be viewed in a national framework but that research itself into all aspects of energy should also be seen as too exclusively a national property. For instance, is it rational to talk of a programme to make the United States independent of the external world in energy matters when it shares thousands of miles of frontier, one common language and many similarities in life-style with Canada? Is the great nuclear reactor debate in Britain one which is too polarised into Britain against the United States. Is it further, one which should have been conducted at an international, or at least, a European level? If brain power as well as energy were regarded as a valuable resource the answer to all these questions would be yes. The giant oil companies have been an interesting example of supranational research and development; it would be unfortunate if with the decline in their influence this mode of operation were to be lost entirely, when it could with profit be used as a model for others.

If narrow interests restricted by geographical frontiers are to be overcome it is urgently necessary that international initiatives be pursued with great vigour. For this reason a proposal of Lord Robens on page 699 is worthy of attention. He suggests the formation of international energy research projects for such matters of common interest as solar energy. It is only around fairly specific objects that international research collaboration is likely to gel, and this as much as anything may be the reason the scientific community has been almost silent on the Kissinger initiative to internationalise energy concerns.

Solar energy would be an ideal project if only because of its world-wide applicability. As Dr Brinkworth points out on page 729 , research and development in solar energy could also be seen as a means of giving aid to developing countries. What is more, the equipment need not be so complex that it is impossible to build and operate except in high technology societies. This too is a subtle consequence of too much national research policy; that the device only works when its maker is on hand and consequently it proves impossible to export. Further, if the work is removed to a government laboratory the economic need for an exportable product may be less to the fore and the formal obstacles to international collaboration much more extensive.

The dangers of nationalism in energy research are great. The antidote to them is not to be found in international committees of bureaucrats but in grass roots action by scientists themselves working across frontiers.

\section{0 years ago}

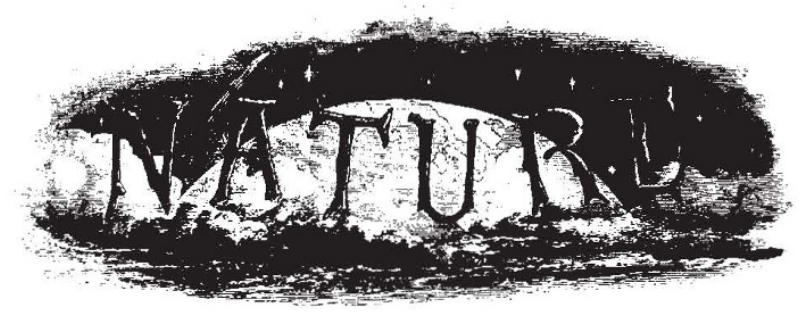

Proposed Issue of Daily Weather Charts of Europe and the North Atlantic

I HAVE the honour to inform you that Capt. Hoffmeyer, Director of the Royal Meteorological Institute of Copenhagen, has sent me a circular announcing his intention to publish daily charts of the weather for the district from $60^{\circ} \mathrm{E}$. to $60^{\circ} \mathrm{W}$. long. and from $30^{\circ}$ to $75^{\circ} \mathrm{N}$. lat. The charts for the three monthsDec. 1873-Feb. 1874-will be published as an experiment.

The cost will be four francs per month, exclusive of postal charges.

Capt. Hoffmeyer states that he can only deal with central offices, and has requested me to undertake these islands as regards the distribution of the charts. I have therefore to announce that I have been instructed by the committee to subscribe for twenty. five copies of these charts, and I shall be happy to supply copies for the three months to any gentleman, at the cost of IIs. to cover carriage from Copenhagen, and postage from London to his address. RobrRT H. ScotT, Direclor Meteorological Office, June 22

From Nature, 10, 146, June 25, 1875. 